\title{
FULL BODY SANITIZING TUNNEL TO TACKLE COVID-19.
}

\author{
Keshav Kumar Jha \\ Department of Mechanical Engineering, KCC Institute of Technology and Management, Gr. Noida, INDIA
}

Keshavjha028@gmail.com

\begin{abstract}
As we know the deadly Coronavirus is spreading very fastly across the world it's almost around 12 months gone but still, there is lack of vaccine manufacturer in India , the only way to stay protect and safe is in the form of taking precautions which may be in the terms of wearing PPE's, masks, hand gloves, washing/sanitizing hands at regular interval and maintaining social distancing. The impact of Coronavirus is very deadly so precaution is very necessary.
\end{abstract}

At the very early stage, the Govt. realized the threat by Coronavirus and implemented a nationwide lockdown which led to a drastic decrease in the chance of community spread. And we all experienced the lockdown and now we are in the second phase of deadly coronavirus and lockdown all over but country can't be in lockdown forever otherwise it's economy will be hit badly.

So, in Unlock 1.0 in first phase all the businesses and shops opened increasing the chance of spread of corona. So, first, all these shops were using sanitizers for the customer to disinfect themselves.

In the rouse of the COVID-19 Pandemic, the dangers of crosscontamination remain soaring high. The odds are especially high with asymptomatic patients who are capable of dispersion of the contagion, even though they might not experience any deadly symptoms of the disease. The Novel Coronavirus is known to stay lively on lifeless surfaces for a prolonged period. Thus, the need of the hour is to introduce machines that would capably eliminate the virus and encumber the rapid spread of it. the "Full Body Sanitizing Machine" - a Personnel Sanitization Enclosure (PSE) that can efficiently eradicate the risks of infection and infection in high traffic areas.

Now, we can take the customer disinfection process a notch above by Full Body Sanitizing Machine which can be constructed very easily and is also very cheap to construct.

It is a Door and tunnel kind, in which 2 sides bounded with the S.S. sheet and the extra 2 edges are exposed for entry and exit purposes and it can also be walled with plastic sheets. When human arrives in the tunnel or machine, at that time the sensor, which is placed at top centre and senses human body and gives output to the motor and motor gets activated and the whole system triggers and all 8-10 sprayers get triggered and starts to spray towards the centre of the tunnel and all 8-10 sprayers spray on the human body and it will routinely stop after 10-15 seconds. Because 10-15 seconds is enough for Sanitization. When Sprayer stops then humans can leave from the front side means the exit side. So, this machine can sanitize 4-5 humans in a minute and 250-300 humans in an hour. [1]
This could be manufactured both in the Tunnel form as well as in a single frame. But the tunnel is most effective because it will concentrate the spray on the human and in the frame design the spray will not work effectively due to wind or any other reason.

So, this report focusses on the development and analysis of these types of tunnels as the time progresses in the pandemic of coronavirus without any effective vaccine these things are going to be in great demand.

Keywords: Covid-19, Sanitization, Full Body, Sanitizer, Tunnel

\section{INTRODUCTION}

The World Health Organisation (WHO) has acknowledged the coronavirus disease 2019 (COVID19) a pandemic. A worldwide harmonized determination is required to stop the additional spread of the virus. A pandemic is defined as "occurring over a wide geographic area and affecting an exceptionally high proportion of the population." The last pandemic stated in the world was the H1N1 flu pandemic in 2009. On 31 December 2019 , a bunch of cases of pneumonia of unknown cause, in the city of Wuhan, Hubei province in China, was informed to the World Health Organisation. In January 2020, a formerly unknown new virus was recognized, afterward named the 2019 novel coronavirus, and samples gained from cases and study of the virus genetics showed that this was the reason for the outburst. This novel coronavirus was named Coronavirus Disease 2019 (COVID-19) by WHO in February 2020. The virus is referred to as SARS-CoV-2 and the associated disease is COVID-19. [3]

Globally, as of 8:38 am CEST, 30 June 2020, there have been 10,117,687 confirmed cases of COVID-19, including 502,278 deaths, reported to WHO. [2] As WHO declared the Covid-19 a pandemic, WHO also advised nations to implement nationwide Lockdowns to prevent the Community Spread of the Virus. That led to home Quarantine of most of the people and the people were told to take every precautionary measure to ensure their safety from the coronavirus like wearing masks, hand gloves, PPE's, washing their hands regularly with soap and use soap whenever way from home, and also to avoid touching their sensitive body parts like eyes, nose, and mouth excessively and unnecessarily. [4]

But a nation can't handle lockdown for a very long time, so, after of continuous lockdown. The lockdown was removed and different services were allowed to reopen with some guidelines. Guidelines were: [5] 
* Only asymptomatic persons shall be allowed. Anyone with a mild cold cough or fever needs to stay at home

* People residing in containment zone shall not come to the office and work from home till containment zone is de-notified

* Face mask and face shield have to be worn at all times.

- Used masks and gloves shall be discarded candle in the yellow colour medical waste bin only.

* The distance of one meter shall be maintained while sitting or walking.

So, as the unlock happened aroused the need for proper sanitizing devices to sanitize the people coming from different places at different offices and businesses.

This device can be placed at any office, shop, or business and it can sanitize the person entering that respective office or place.

So, as there is no vaccine available for coronavirus, the thing that we can do is we can keep ourselves and our surroundings clean and sanitize. Now, let's understand what is meant by CLEANING and SANITIZING.

\section{CLEANING AND SANITIZING}

\section{CLEANING}

Cleaning is a procedure that will evacuate soil and forestall the amassing of food deposits which may break down or bolster the development of infection causing living beings or the creation of poisons.

Below are the 5 essential sorts of cleaning mixes and their significant capacities:

1. Basic Alkalis - Soften the water (by precipitation of the hardness particles), and saponify fats (the concoction response between a soluble base and fat in which cleanser is created).

2. Complex Phosphates - Emulsify fats and oils, scatter and suspend oils, peptize proteins, mollify water by sequestering, and give rinsability attributes without being destructive.

3. Surfactant - (Wetting Agents) Emulsify fats, scatter fats, give wetting properties, structure bubbles, and give rinsability attributes without being destructive.

4. Chelating - (Organic mixes) Soften the water by sequestering, forestall mineral stores, and peptize proteins without being destructive.

5. Acids - Good at mineral store control; and mollify the water. [6]

Some properties of Good Cleaners: [6]

* Quick and complete solubility.

* Good wetting or penetrating action.

* Dissolving action of food solids.

* Emulsifying action on fat.

* Deflocculating, dispersing, or suspending action.

* Good rinsing properties.

* Complete water softening power.

* Noncorrosive on metal surfaces.

* Germicidal action.

* Economical to use.

Factors affecting Cleaning Efficiency: [6]

+ Selecting the right cleaner for the job.

+ Increasing the temperature of the cleaning solution so that the strength of the bond between the soil and surface is decreased, the viscosity is decreased, and the solubility of the soluble materials and the chemical reaction rate is increased.

+ Increasing the turbulence "elbow grease".
+ Increasing the time, the cleaner has contact with the surface needing cleaning. Increasing concentration.

+ Concentration is the least effective variable to change in cleaning.

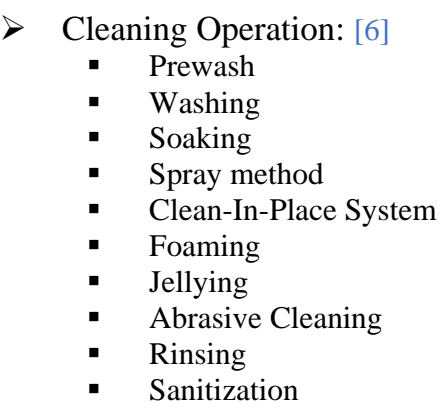

\section{SANITIZATION}

It is a procedure either by utilizing heat or a substance focus that will decrease the bacterial check, remembering pathogens to a protected level for surfaces and human skin.

It is important to differentiate and describe certain terms:

- Sterilize refers to the systematic destruction and elimination of all alive bacteria.

- Disinfect refers to inorganic objects and the annihilation of all nonsexual cells (not spores).

- Sanitize refers to the decrease of bacteria to stages measured safe from a civic fitness view. [6]

The essential purpose behind the utilization of compelling sterilizing methodology is to demolish those infection life forms which might be available on gear in the wake of cleaning and in this manner forestall the exchange of such living beings to someone else. Furthermore, purifying methods may forestall the obstruction of microorganisms in different mechanical procedures that rely upon unadulterated societies.

Hand sanitizers work by evacuating the external layer of oil on your skin. On the off chance that you don't utilize enough hand sanitizer - or you don't focus on it altogether - under $99.9 \%$ of the germs on your hands will be murdered. There are two or three different circumstances in which hand sanitizers probably won't be as viable as you trust.

Alcohol-based hand sanitizers help to discourage the increase of microbes and illness causing tiny viruses, particularly in busy places like schools and workplaces. As indicated by examines, 1 out of 5 folks do not routinely wash their hands. Of the folks who do, $70 \%$ don't utilize soap.

The principle fixing found close by sanitizers is ethyl alcohol or Ethanol, in which the synthetic equation can be composed as $\mathrm{C}_{2} \mathrm{H}_{5} \mathrm{OH}(\mathrm{L})$ or $\mathrm{CH}_{3} \mathrm{CH}_{2} \mathrm{OH}(\mathrm{L})$. Different fixings found close by sanitizers are Water, Glycerine, Isopropyl Myristate, Propylene Glycol, Tocopherol Acetic acid derivation, Amino methyl Propanol, Carbomer, Fragrance.

"A way to make Natural Sanitizer at home: Mix aloe Vera gel, non-compulsory glycerine, and rubbing alcohol in a small container. Complement cinnamon essential oil \& tea tree oil \& add a drop or two of any other oils for scent. Lemongrass, Orange, Lavender, and Peppermint will be better picks."

\section{CHEMICAL SANITIZERS}


There is a widespread assortment of branded synthetic brews whose property crush or restrain the development of germs. A considerable lot of these synthetics, in any case, are not reasonable for use on food-contact shells since they may erode, stain, or leave a film on a superficial level. Others might be profoundly poisonous or excessively costly for reasonable use.

Different types of Chemical Sanitizers:

+ Chlorine-based

+ Iodophors (soluble complexes of Iodine)

+ Quaternary Ammonium Compounds

+ Hydrogen Peroxide

+ Peroxyacetic Acid (PAA)

+ Peroxides

+ Fatty Acid Sanitizers

+ Acid-Anionic Sanitizers

+ Alcohol-based Sanitizer

Here, we are going to talk about Alcohol-Based Sanitizer.

\section{ALCOHOL BASED SANITIZER}

Hand sanitizer is a fluid, gel, or froth commonly used to diminish irresistible operators on the hands. In many settings, handwashing with cleanser and water is commonly liked. Hand sanitizer is less convincing at slaughtering precise sorts of microbes, for example, Norovirus \& Clostridium difficile and dissimilar to detergent and water, it can't expel unsafe synthetic brews. Individuals may incorrectly clear off the hand sanitizer before it has dried, and some are less powerful because their alcohol fixations are excessively low. [12]
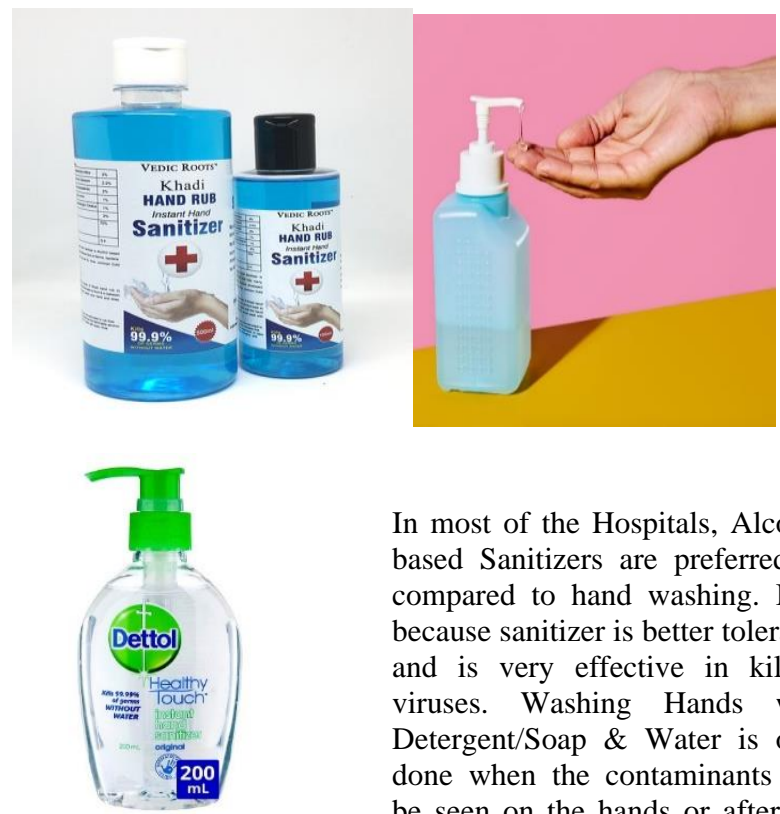

In most of the Hospitals, Alcohol based Sanitizers are preferred as compared to hand washing. It is because sanitizer is better tolerated and is very effective in killing viruses. Washing Hands with Detergent/Soap \& Water is only done when the contaminants can be seen on the hands or after the use of Toilet. And use of non-alcohol-based sanitizers is not recommended as it does not do anything.

Alcohol Based Brews of Sanitizer contains Isopropyl Alcohol, Ethanol or Ethyl Alcohol, n-Propanol. The most effective version will be with alcohol percentage between $60 \%$ to 95\%. Extra precautions should be taken after using the alcohol-based sanitizer as it is flammable. These work on almost all of the germs except the spores.
Mixes like glycerine could also be further to forestall drying of the skin. Some types contain scents; but these are disheartened because of the danger of aversions. Non-alcohol based types generally comprise benzalkonium chloride or triclosan however are less effectual than alcohol-based ones.

Alcohol is used as an associate in Nursing antibacterial since 1363 with proof to support its use within the late 1800s. Alcohol Sanitizer has been ordinarily utilized in Europe since the Eighties. The alcohol-based form is on the WHO's List of Essential Medicines, the nonviolent and best medicines required during a health system. The extensive value within the emerging world is vis-à-vis US $\$ 1.40$ $\$ 3.70$ per metric capacity unit bottle.

When using an alcohol-based hand sanitizer:

1. Apply to the palm of one hand.

2. Rub hands together.

3. Rub the produce over all surfaces of hands and fingers until hands are dry.

4. Do not go near flame or any burning object during applying sanitizer.

Alcohol Sanitizers might not be effectual if the hands are slimy or evidently unclean. In hospitals, the hands of aid employees are typically contaminated with pathogens, however rarely unclean or oily. While in community, oily and dirty hands are common from activities like managing food, enjoying sports, farming and being active outside. Likewise, impurities like metals and insecticides (generally found out-of-doors) can't be detached by sanitizers.

Some commercially-available hand sanitizers (and on-line recipes for home-cured rubs) have alcohol concentrations that area unit too low. This makes them less effective at killing germs. Poorer individuals in developed countries and other people in developing countries could realize it tougher to urge a hand sanitizer with an efficient alcohol concentration. dishonest labelling of alcohol concentrations has been a tangle in British Guiana.

But during this state of affairs of coronavirus, hand sanitizers with a minimum of seventieth alcohol $\mathrm{v} / \mathrm{v}$ area unit the foremost effective ones. The govt. too has issued a tenet to use hand sanitizers with AN alcohol level additional or adequate seventieth. [12]

\section{Drawbacks of hand sanitizer}

There are unit bound things throughout that handwashing with soap and water area unit most well-liked over hand sanitizer, these include: eliminating microorganism spores of Clostridioides difficile, parasites like Cryptosporidium, and bound viruses like norovirus looking on the concentration of alcohol within the sanitizer $(95 \%$ alcohol was seen to be only in eliminating most viruses). Also, if hands area unit contaminated with fluids or alternative visible contaminants, hand laundry is most well-liked furthermore as once exploitation the rest room and if discomfort develops from the residue of alcohol sanitizer use. moreover, office states hand sanitizers aren't effective in removing chemicals like pesticides. [8] 
WHO Formulation for Hand Sanitizer: [12]

Formulation 1:

\begin{tabular}{|c|c|c|}
\hline FORMULATION 1 & 10-L prep. & Active ingredient (v/v) \\
\hline Ethanol 96\% & $8333 \mathrm{~mL}$ & $80 \%$ \\
\hline Glycerol 98\% & $145 \mathrm{~mL}$ & $1.45 \%$ \\
\hline Hydrogen peroxide 3\% & $417 \mathrm{~mL}$ & $0.125 \%$ \\
\hline Distilled water & added to $10000 \mathrm{~mL}$ & $18.425 \%$ \\
\hline
\end{tabular}

Formulation 2:

\begin{tabular}{|c|c|c|}
\hline FORMULATION 2 & 10-L prep. $\quad \forall$ & Active ingredient $(v / v)$ \\
\hline Isopropyl alcohol $99.8 \%$ & $7515 \mathrm{~mL}$ & $75.15 \%$ \\
\hline Glycerol 98\% & $145 \mathrm{~mL}$ & $1.45 \%$ \\
\hline Hydrogen peroxide $3 \%$ & $417 \mathrm{~mL}$ & $0.125 \%$ \\
\hline Distilled water & added to $10000 \mathrm{~mL}$ & $23.425 \%$ \\
\hline
\end{tabular}

\section{Production; COVID-19 Pandemic}

In 2010 the planet Health Organization made a guide for producing hand sanitizer, that received revived interest in 2020 due to shortages of hand sanitizer within the wake of the COVID-19 pandemic. Dozens of alcohol and fragrance manufactures switched their producing facilities from their traditional product at hand sanitizer. to stay up with the demand, native distilleries started victimisation their alcohol to create hand sanitizer. Distilleries manufacturing hand sanitizer originally existed in a very legal grey area within the u. s., till the Alcohol and Tobacco Tax and Trade Bureau declared that distilleries might manufacture their sanitizer while not authorization. [7]

There are cautions against making your hand sanitizer. Some widely-circulated home recipes are ineffective or even poisonous.

\section{Few Examples of Disinfectant Robots or Machine}

\section{$\rightarrow$ NEVOA - Room Disinfecting System}

Besides non-chemical medical care ways like ultraviolet (UV) lightweight, there are unit different ways in which to quickly kill bacterium - by using chemical disinfectants Scottish company Nevoa develops robotic disinfectant solutions that demonstrate high effectiveness against SARS-CoV-2, as an example. Their no-touch hospital medical care mechanism, Nimbus, utilizes a solution resolution for disinfecting rooms and surfaces. Nimbus atomizes their microburst cleanup solution, an EPAregistered hospital-grade disinfectant, and fully removes its disinfectant cloud once finishing the cleansing method. [15]

\section{$\rightarrow$ XENEX Disinfection Services - Xenon Light-Based} Disinfection System

Most ultraviolet light disinfection devices use mercury gas bulbs as a light supply with an efficient wavelength of $254 \mathrm{~nm}$. The ultraviolet light emitted by nonaggressive mercury bulbs is delivered in a very continuous stream that gently accumulates to microorganism fatal doses. pulsed xenon ultraviolet (PX-UV) is an alternate to traditional ultraviolet ways giving high-intensity pulse germicidal ultraviolet light. it is emitted in brief, high-intensity pulses, presumably requiring a shorter length of exposure, to attain fatal doses. PX-UV light potentially possesses greater efficacy than other forms of

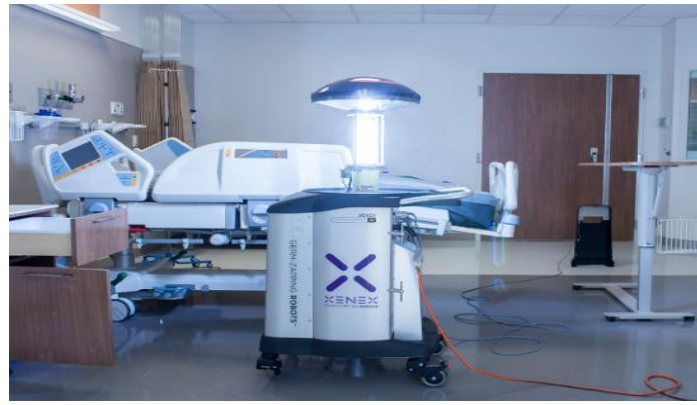

UV, such as mercury UV, because of its broad-spectrum and greater intensity.

The US-based company Xenex Disinfection Services makes Light Strike robots that use pulsed xenon light to sterilize different hospital areas. Xenex's patented pulsed xenon Full Spectrum UV room disinfection system removes injurious bacteria, viruses, and microbes. [15]

\section{$\rightarrow$ UVD Robots - UV Disinfection Robot}

Ultraviolet light is clinically recognized as an effective sterilizer. Ultraviolet lamps outfit small spaces, such as hospital rooms, as well as bigger areas like airports and malls.

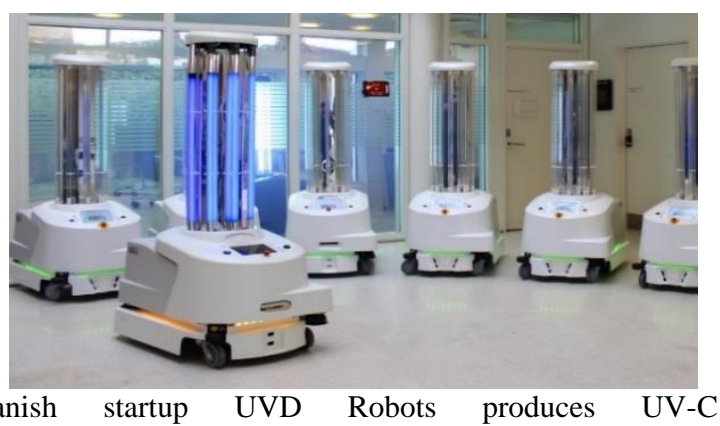

Danish startup UVD Robots produces UV-C and other units in infirmaries. The machines produce ultraviolet light that decontaminates surfaces by ripping apart strands of virus DNA. The robot scans the atmosphere using LiDAR technology and creates a digital map. It then relies on Simultaneous Localization and Mapping (SLAM) to steer and function completely freely. The robot functions only when people are not in the vicinity, using its sensors to detect motion and shutting down the UV lights off if someone is around. [15]

+ XAG - Drone-Based Disinfection

Agricultural drones are already within the act as autonomous exactitude spraying machines, as they're appropriate for releasing disinfectants publicly places. These drones are quicker and thus able to cowl much more distances compared to ancient strategies whereas keeping human operators out of potential exposure to each the virus and therefore the disinfectant. 


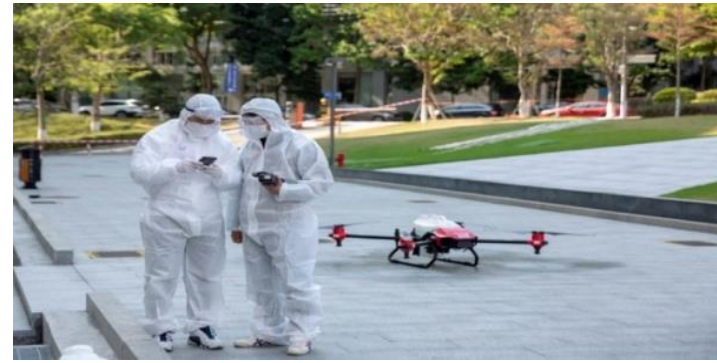

Chinese company XAG produces industrial unmanned Aerial Systems (UAS) and recognized a special fund for a drone disinfection operation to fight COVID-19. the corporate uses its own agricultural drones to disperse sterilizers to enhance public sanitation and reduce the danger of communication the virus over surface contact, additionally branded as fomites. [15]

\section{$\rightarrow$ NEOLIX - Autonomous Vehicles for Disinfecting}

Neolix is a self-driving distribution automobile startup from China that promoted its vans in answer to the coronavirus situation. Robotic vehicles get-up-and-go around the city and atomize the sanitizers to help control the blowout of the virus. Neolix's vans use a blend of sensors and high-definition maps in order to sense and evade obstacles with a high degree of accurateness. Moreover, their battery system allows travel of up to 100 kilometers (62 mi) after a single charge. [15]

\section{LIST of EQUIPMENT and COMPONENTS NEEDED}

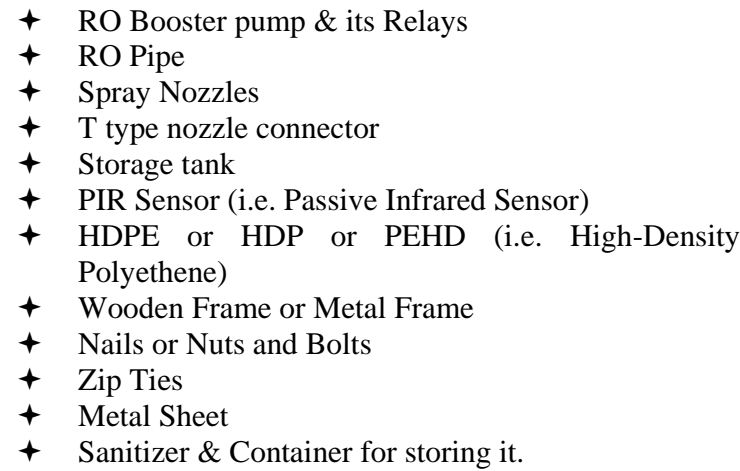

\section{RO Booster Pump}

The purpose of the reverse osmosis booster pump is to improve water pressure going into the Ro unit. Similarly, we will use the booster pump to increase the pressure in the flow of sanitizer in the pipe.

Because the nozzle works on the principle of Bernoulli's and it converts the Kinetic Energy of the flow into pressurized energy, which will help us in getting a nice mist through a nozzle.

Booster Pumps are used when the supply of water has less than 50PSI. Here, we have no pressure because we will be storing the sanitizer in a container on the ground.

There are two types of electric pumps frequently used for Booster Systems:
- Booster Pumps are designed to improve water pressure to a perfect level as it enters your RO unit.

- Demand or Delivery Pumps are typically required to maneuver water from a vessel to associate application - for instance, to feed pressurised water to an icebox, ice maker, or a sink tap. [10]

\section{* Pump Working:}

Booster pump works by a rotating motor moving a diaphragm to create piston action sucking in water through the inlet and in turn forcing the water out through the outlet port when the diaphragm moves in the other direction. The booster pump should be plumbed in with a low-pressure sensor to prevent dry running.

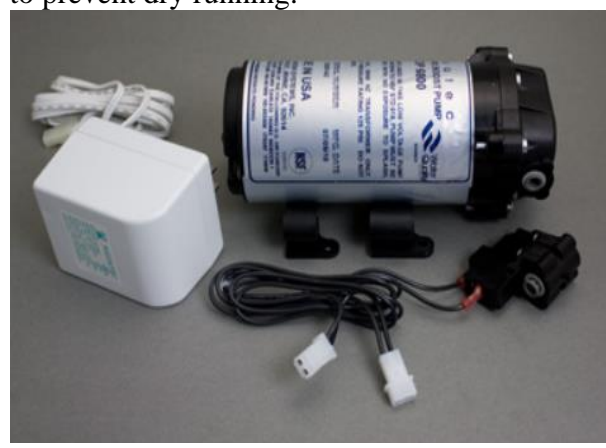

Fig: A RO Booster Pump

* How to increase the pressure:

Permeate pumps can easily be retrofitted to upgrade existing RO systems. Adding an electric booster pump increases the RO production rate, boosts the pressure tank storage volume, rejects more contaminants, and increases faucet flow rate even if the reverse osmosis membrane pressure rating is met by the water supply. [10]

\section{* Difference between RO Pump and Pressure Pump:}

The pressure that the booster pump should give is the variation between the desired system pressure and the existing pump pressure. This pressure variation is the pressure boost that the booster pump has to offer at the specified rate of flow to meet the applying needs.

A booster pump will be controlled by a pressure tank and pressure switch, with a Cycle Stop Valve. Controls for a booster pump ought to be ready to deliver water on demand once a faucet is opened, and switch off the pump once no water is getting used.

A booster pump boosts water pressure and, in several cases, improves the rate of flow. A booster pump works a bit like a fan. a fan has blades that whirl to extend air movement, and a booster pump has a blade within that will increase water flow and pressure in the same fashion. [10]

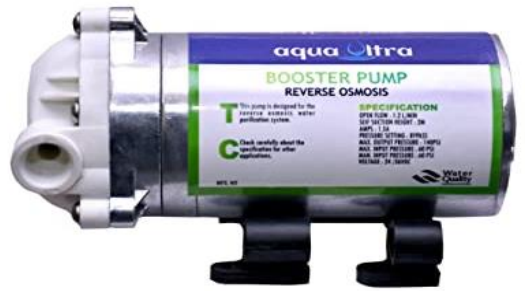

Fig: RO Booster Pump 


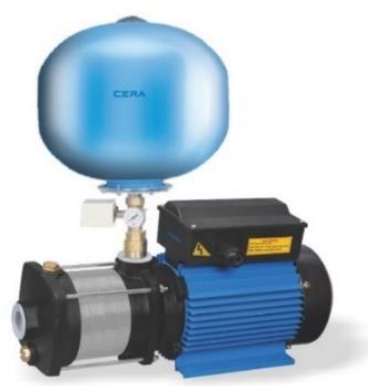

Fig: Pressure Booster Pump

VII. PIR Sensor

A passive infrared device (PIR device) is an electronic sensor that measures infrared (IR) light from objects in its field of view. they're most frequently employed in PIR-based motion detectors. PIR sensors are normally employed in security alarms and automatic lighting applications.

PIR sensors notice general movement however don't offer info on who or what moved. For that purpose, a vigorous IR device is needed.

PIR sensors are normally known as simply "PIR", or generally "PID", for "passive infrared detector". The term passive refers to the very fact that PIR devices don't radiate energy for detection functions. They work entirely by detecting infrared emission (radiant heat) emitted by or reflected from objects. [19]

PIR sensors permit you to sense motion, nearly always used to sight whether or not a human has affected in or out of the sensors range. they're little, cheap, low-power, straightforward to use, and do not wear out. For that reason, they're unremarkably found in appliances and gadgets employed in homes or businesses. they're typically spoken as PIR, "Passive Infrared", "Pyroelectric", or "IR motion" sensors.

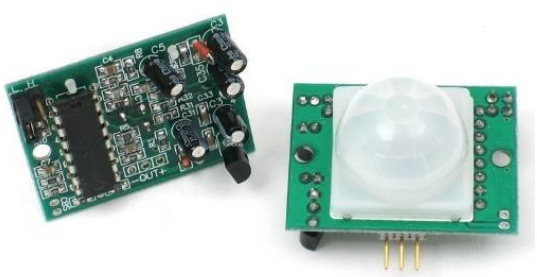

PIRs are product of a pyroelectrical device, which may observe levels of infrared emission. Everything emits some low-level radiation, and the hotter something is, a lot of radiation is emitted. The device during a motion detector is split into 2 halves. the rationale for that we tend to looking to obser'• motion (change), not average IR levels. the 2 halves are wired $\mathrm{c}_{0}$ so they cancel one another out. If one half sees additional or le IR radiation than the opposite, the output can swing high or low

Along with the pyroelectrical device may be a bunch us supporting electronic equipment, resistors, and capacitors. It appears that the majority little hobbyist sensors use the BISS0001 ("Micro Power PIR Motion Detector IC"), doubtless a really cheap chip. This chip takes the output of the device and does some minor process on that to emit a digital output pulse from the analog device. [14] Older PIRs looked like this:

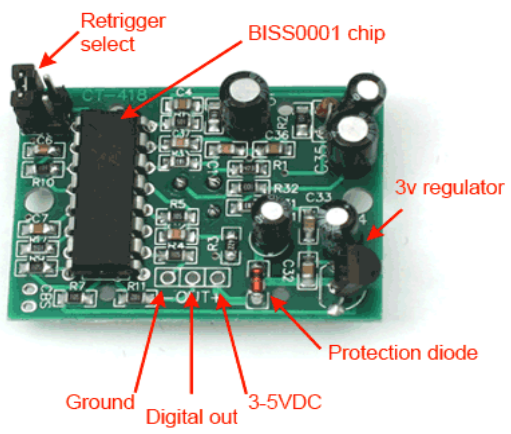

New PIRs have more adjustable settings and have a header installed in the 3-pin ground/out/power pads:

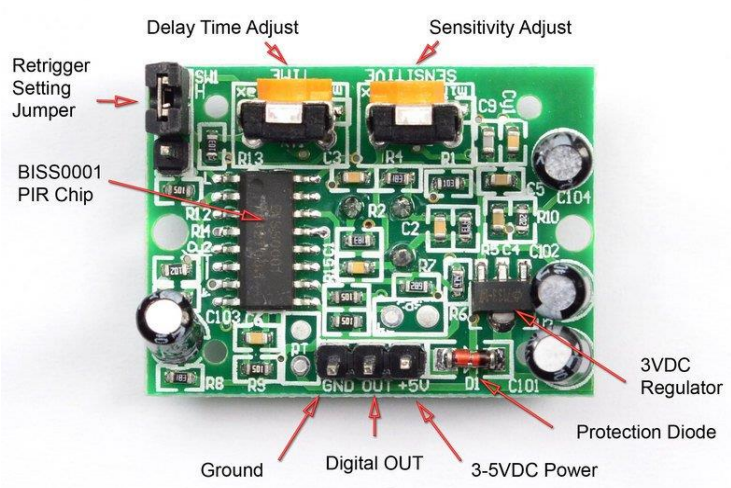

For many basic projects or product that require to notice once someone has left or entered the area or has approached, PIR sensors are nice. they're low power and low value, pretty rugged, have a good lens field of view and are straightforward to interface with.

Note that PIRs won't tell you how many folks are around or how close they are to the sensor, the lens is often fixed to a certain angle and distance (although it can be hacked sometimes) and they are also sometimes set off by house pets. Experimentation is key! [14]

\section{- Some Basic Stats}

Nearly all PIRs will have slightly different specifications, although they all pretty much work the same. If there's a datasheet, you'll want to refer to it.

\section{Shape: Rectangular}

Output: Digital pulse high $(3 \mathrm{~V})$ when triggered (motion detected) digital low when idle (no motion detected). Pulse lengths are determined by resistors and capacitors on the PCB and differ from sensor to sensor.

- Sensitivity range: up to 20 feet $(6$ meters $) 110^{\circ} \times 70^{\circ}$ detection range

- Power supply: 5V-12V input voltage for most modules (they have a $3.3 \mathrm{~V}$ regulator), but $5 \mathrm{~V}$ is ideal in case the regulator has different specs

- BIS0001 Datasheet (the decoder chip used)

- RE200B datasheet (most likely the PIR sensing element used)

- $\quad$ NL11NH datasheet (equivalent lens used) [14] 


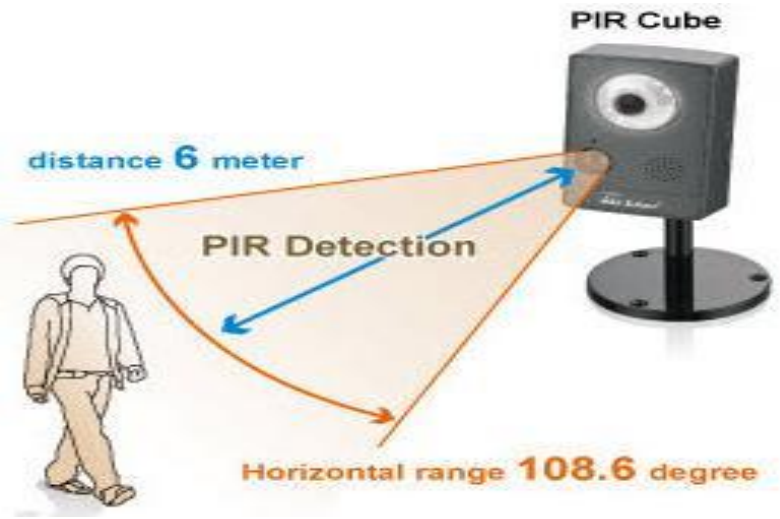

VIII. SANITIZER \& and Its usage Guidelines The guidelines issued by WHO for the production of Alcohol-based Hand Sanitizers are already shown in the report. [8][9][12]

D All indoor areas such as entrance lobbies, corridors, and staircases, escalators, elevators, security guard booths, office rooms, meeting rooms, cafeteria should be mopped with a disinfectant with $1 \%$ sodium hypochlorite or phenolic disinfectants. The guidelines for preparing fresh $1 \%$ sodium hypochlorite solution. [20]

$\rightarrow$ Guideline for preparing 1\% Sodium Hypochlorite Solution:

\begin{tabular}{|l|l|l|}
\hline Product & Available chlorine & lpercent \\
\hline Sodium hypochlorite - liquid bleach & $3.5 \%$ & 1 part bleach to 2.5 parts water \\
\hline Sodium hypochlorite - liquid & $5 \%$ & 1 part bleach to 4 parts water \\
\hline $\begin{array}{l}\text { NaDCC (sodium dichloro- } \\
\text { isocyanurate) powder }\end{array}$ & $60 \%$ & 17 grams to 1 litre water \\
\hline NaDCC $(1.5 \mathrm{~g}$ tablet) - tablets & $60 \%$ & 11 tablets to 1 litre water \\
\hline Chloramine - powder & $25 \%$ & $80 \mathrm{~g}$ to 1 litre water \\
\hline Bleaching powder & $70 \%$ & $7 \mathrm{~g}$ to 1 litre water \\
\hline Any other & As per manufacturer's Instructions \\
\hline
\end{tabular}

\section{HIGH-DENSITY POLYETHENE (HDPE/PEHD/HDP)}

High-density polythene (HDPE) or polythene high-density (PEHD) may be a thermoplastic compound created from the monomer ethylene. it's generally referred to as "alkathene" or "polythene" once used for HDPE pipes. With a high strengthto-density ratio, HDPE is employed within the production of plastic bottles, corrosion-resistant piping, geomembranes, and plastic lumber. HDPE is often recycled and has the number "2" as its organic compound identification code. [13]

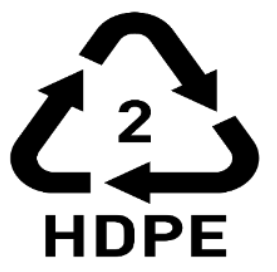

HDPE is thought for its high strength-to-density ratio. The density of HDPE will vary from 930 to $970 \mathrm{~kg} / \mathrm{m} 3$. though the density of HDPE is barely marginally over that of low-density polythene, HDPE has very little branching, giving it stronger unit forces and enduringness than LDPE. The difference in strength exceeds the difference in density, giving HDPE a better specific strength. it's additionally tougher and additional opaque and may face up to somewhat higher temperatures $\left(120{ }^{\circ} \mathrm{C} / 248{ }^{\circ} \mathrm{F}\right.$ for brief periods). High-density polythene, in contrast to plastic, cannot face up to commonly needed autoclaving conditions. the dearth of branching is ensured by an acceptable selection of catalyst (e.g., Ziegler-Natta catalysts) and reaction conditions. [13]

HDPE is resistant to many different solvents.

\begin{tabular}{|l|l|}
\hline Density & $940 \mathrm{~kg} / \mathrm{m}^{3}$ \\
\hline Melting Point & $130.8^{\circ} \mathrm{C}$. \\
\hline Temperature of crystallization & $111.9^{\circ} \mathrm{C}$. \\
\hline Latent heat of fusion & $178.6 \mathrm{~kJ} / \mathrm{kg}$. \\
\hline $\begin{array}{l}\text { Thermal conductivity } \\
\text { Specific Heat Capacity }\end{array}$ & $0.44 \mathrm{~W} / \mathrm{m} .{ }^{\circ} \mathrm{C}$. at ${ }^{\circ} \mathrm{C}$. \\
\hline $\begin{array}{l}\text { Specific heat (solid) } \\
\text { Crystallinity }\end{array}$ & 1330 to $2400 \mathrm{~J} / \mathrm{kg}-\mathrm{K}$ \\
\hline
\end{tabular}

Fig: Thermophysical properties of High-Density Polyethylene (HDPE)

The physical properties of HDPE will vary counting on the moulding method that's used to manufacture a selected sample;

to some extent, a crucial issue is that the international

standardized testing ways used to spot these properties for a selected process. for instance, in rotational Molding, to spot the environmental stress crack resistance of a sample, the Notched

Constant Tensile Load test (NCTL) is put to use. [13]

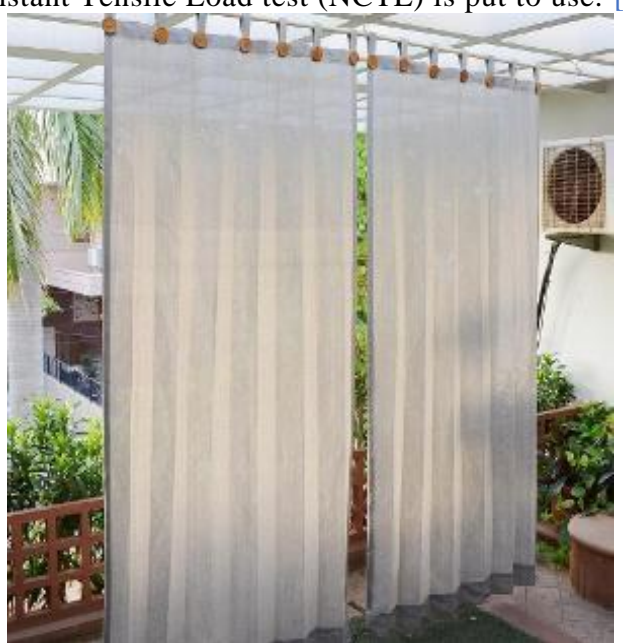

Fig: HDPE Curtain

\section{RELAYs}

A relay is an electrically operated switch. It consists of a collection of input terminals for one or multiple management signals, and a 
collection of operative contact terminals. The switch might have any variety of contacts in multiple contact forms, similar to creating contacts, break contacts or combos therefrom

Relays are used wherever it's necessary to manage a circuit by a freelance low-power signal, or wherever many circuits should be controlled by one signal. Relays were initial utilized in long-distance telegraph circuits as signal repeaters: they refresh the signal coming back in from one circuit by transmission it on another circuit. Relays were used extensively in telephone exchanges and early computers to perform logical operations.

The traditional type of a relay uses an electromagnet to shut or open the contacts, however alternative operational principles are fancied, similar to in solid-state relays that use semiconductor properties for management while not hoping on moving components. Relays with graduated operational characteristics and typically multiple operating coils are used to shield electrical circuits from overload or faults; in fashionable power systems, these functions are performed by digital instruments still known as protective relays.

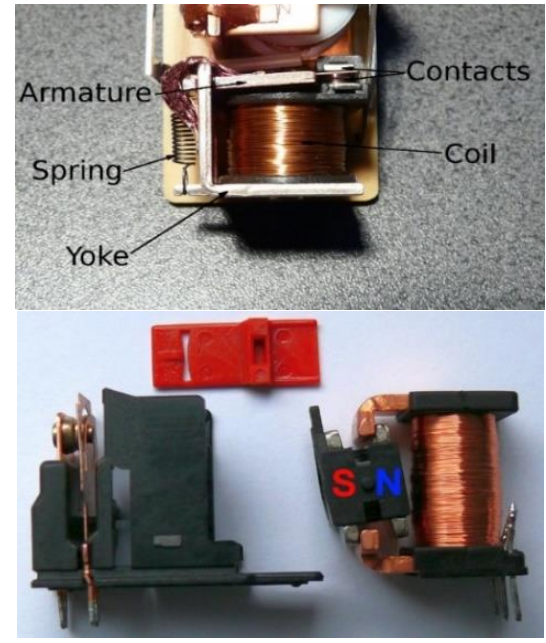

Latching relays require most effective a single pulse of management power to function the switch persistently. Another pulse implemented to a 2nd set of control terminals, or a pulse with opposite polarity, resets the transfer, whilst repeated pulses of the equal kind have no effects. Magnetic latching relays are beneficial in programs when interrupted electricity should no longer affect the circuits that the relay is controlling. [21]

\section{* Types of RELAYs:}

+ Contactor:

A contactor is a heavy-duty relay

with higher contemporary scores, used for switching electric vehicles and lighting loads. Continuous presentday rankings for common contactors range from $10 \mathrm{amps}$ to numerous hundred amps. High-modern-day contacts are made with alloys containing silver. The unavoidable arcing reasons the contacts to oxidize; however, silver oxide is still a great conductor. Contactors with overload

protection devices are frequently used to begin motors.

+ Overload Protection Relay

Electric motors want overcurrent safety to prevent harm from over-loading the motor, or to guard against brief circuits in connecting cables or internal faults in the motor windings. The overload sensing gadgets are a shape of heat operated relay wherein a coil heats a bimetallic strip, or wherein a solder pot melts, to operate auxiliary contacts. These auxiliary contacts are in collection with the motor's contactor coil, so that they turn off the motor when it overheats. [21] and many more...

\section{SPRAY NOZZLE}

A spray could be a dynamic assortment of drops spread in a gas. the method of forming a spray is understood as atomization. a spray nozzle could be a device used to generate a spray. the 2 main uses of sprays are to distribute material over a cross-sectional and to come up with liquid expanse. There are thousands of applications during which sprays enable material to be used most with efficiency. The spray characteristics needed should be understood so as to pick the foremost acceptable technology, best device, and size. [11]

A Spray Nozzle may be a exactitude device that facilitates the dispersion of liquid into a spray. Nozzles are used for 3 purposes: to distribute a liquid over a region, to extend liquid expanse, and build impact force on a solid surface. a good type of spray nozzle applications uses variety of spray characteristics to explain the spray.

Spray nozzles may be classified supported the energy input used to cause atomization, the breakup of the fluid into drops. Spray nozzles can have one or a lot of outlets; a multiple outlet nozzle is thought as a compound nozzle. Spray nozzles vary from heavy industrial uses to light-duty spray cans or spray bottles. [11]

\section{* Sprayer Fluid Rate}

- Fluid rate refers to the nozzle's output volume (GPM), that is predicated on the sprayer pump's specifications.

- Could be a specific tank-to-nozzle GPM (Gallons Per Minute) required for volume output over a select space. Or a particular volume rate for sensitive chemical delivery.

- Choose a sprayer and system that gives the general characteristics to deliver at the nozzle; sprayer pumps may be changed for spraying systems. [22]

\section{* Sprayer Fluid Pressure}

- $\quad$ Fluid pressure refers to the nozzle's output pressure (psi)

- Most sprayer psi relies on the sprayer pump and correlates directly with horizontal and vertical spray distance.

- Recognize if a selected pump-to-nozzle psi is needed to achieve target areas with spray fluid, as in garden, vineyard, from-road applications. [22]

\section{$>$ Few Types of Nozzles}

1. Single Fluid Nozzle

Single-fluid or hydraulic spray nozzles utilize the K.E. of the liquid to interrupt it up into droplets. This most generally used kind of spray nozzle is more energy efficient at producing surface area than most alternative varieties. as the fluid pressure will increase, the flow through the nozzle will increase, and therefore the drop size decreases. several configurations of single fluid nozzles are used reckoning on the spray characteristics desired.

2. $\quad$ Plain Orifice Nozzle

The simplest single fluid nozzle may be a plain orifice nozzle as shown within the diagram. This nozzle usually produces very little if any atomization however directs the stream of liquid. If the pressure drop is high, a minimum of twenty-five bars $(2,500 \mathrm{kPa})$, the material is usually finely atomized, as in a diesel injector. At lower pressures, this kind of nozzle is commonly used for tank clean up, either as a set position 


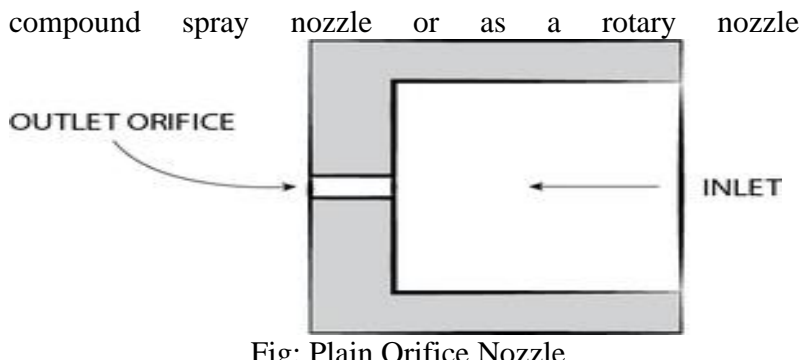

Fig: Plain Orifice Nozzle

3. Shaped Orifice Nozzle

The shaped orifice uses a semi-circular shaped inlet and a V notched outlet to cause the flow to spread out on the axis of the $\mathrm{V}$ notch. A flat fan spray results which is useful for many spray applications, such as spray painting. [11]

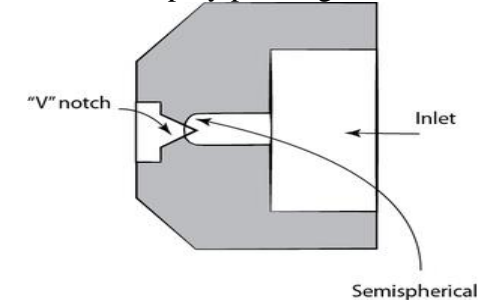

Fig: Flat fan spray pattern spray nozzle

\section{CONSTRUCTION}

Full body sanitizing machine is simple in structure it consists of several simple parts that are easily available in all markets, it's size and parts depending on its application and mode of use, we are making it as a project purpose so the parts or components used is according to it. For commercial and domestic purposes, it may vary.

It consists of parts like RO booster pump, RO pipe, spray nozzles, frame, HDPE polythene, storage tank, human body detection sensor, and storage tank, etc.

The frame is made in any shape as required here we make it in the cuboidal shape with dimensions $(4 * 3 * 7)$ feet of the iron square rod which is covered by metal sheet from the side, top and bottom and the entry and exit are covered by HDPE curtains. Nozzles are fitted at the required position we chose to fit 8 nozzles at different locations so that it can cover the whole body at a time. Nozzles are connected to the motors via pipe and motor is also connect with storage tank. Initially, all the process starts with PIR sensor which senses human body and is responsible for the whole sanitizing process.

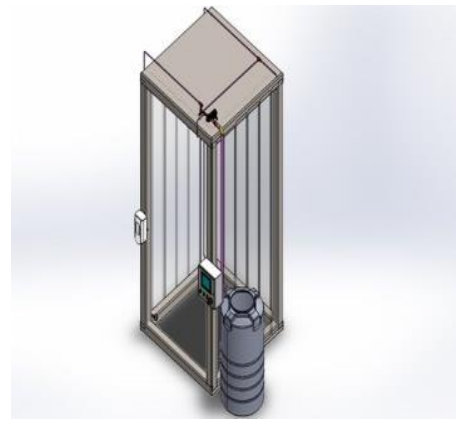

XIII. WORKING
Full body sanitizing machines work in a closed cycle, which means a cycle of work that must go on.

It starts with the detection of the human body with the PIR (Passive Infrared) sensor which transfers the signal to its relay who is responsible for the transfer of signal to the motor which is connected with the storage tank and another side is connected with the spray nozzles fitted in the cabin once the sensor senses the presence of human body motor starts spraying through nozzles up to 10 seconds and after which it stops automatically the time duration of sanitizing can be changed according to require while coding for the sensor and after 10 seconds it stops and remains in the closed position until sensor would detect any human body.

For Block Diagram see Fig. 1.

\section{CALCULATION}

Here we have to calculate the total discharge: "Q" is Total discharge

$\mathrm{Q}=\left(\mathrm{q}_{1}+\mathrm{q}_{2}+\mathrm{q}_{3}+\ldots .+\mathrm{q}_{\mathrm{n}}\right)$ here $\mathrm{q}_{1}, \mathrm{q}_{2} \ldots \mathrm{q}_{\mathrm{n}}$ are the discharge through "n" nozzles

$\mathrm{Q}=\mathrm{A} \times \mathrm{V}$

Where, $A=$ area of cross section

$$
\mathrm{V}=\text { velocity }
$$

Here number of nozzles " $n$ " is 8 .

Now we have to compare the discharge of pump to the nozzles

Discharge pressure: 140PSI or 9.52643atm or 9.65266bar Flow rate: $100 \mathrm{GPD}$ or $0.3785412 \mathrm{~m}^{3} / \mathrm{s}$

1 Gallon $=3.785$ litres

Discharge through pump $=$ Total discharge through all nozzles + losses

$$
\begin{aligned}
& 0.3785412 \mathrm{~m} 3 / \mathrm{s}=\mathrm{Q}+\text { losses } \\
& =\left(\mathrm{q}_{1}+\mathrm{q}_{2}+\mathrm{q}_{3}+\ldots .+\mathrm{q}_{\mathrm{n}}\right)+\text { losses }
\end{aligned}
$$

*all nozzles have same dimensions so area will be same. So, we can write;

$$
=8 \times(\text { area } \times \text { velocity })
$$

Discharge of 1 nozzle $=0.04531 \mathrm{~m}^{3} / \mathrm{s}$

Discharge through 8 nozzles

$$
\begin{aligned}
& =8 \times 0.04531 \\
& =0.36248 \mathrm{~m}^{3} / \mathrm{s}
\end{aligned}
$$

Nozzle discharge $=\mathrm{A} \times \mathrm{V}$

$$
0.04531=\left(\pi \div 4 \times(0.007)^{2}\right) \times \mathrm{V}
$$

$\mathrm{V}=1177.35 \mathrm{~m} / \mathrm{s}$ from 1 nozzle

Pump discharge $=$ Nozzle discharge + Losses $0.3785412 \mathrm{~m}^{3} / \mathrm{s}=0.36248 \mathrm{~m}^{3} / \mathrm{s}+$ Losses Losses $=0.0160612 \mathrm{~m}^{3} / \mathrm{s}$

Pump Efficiency $=$ Actual discharge/Theoretical discharge

$$
\begin{aligned}
& =0.36248 / 0.3785412 \\
& =0.96=\mathbf{9 6} \%
\end{aligned}
$$

NOTE: All the Calculations done and Results obtained are Theoretical due to lockdown in state. Results may differ when implemented practically.

\section{CONCLUSION}


At the end of the report, we can conclude that this tunnel could be very helpful in tackling the Covid-19 pandemic during the unlock period when all the businesses and shops are open for the general public and there is a greater chance of community spread among the people. This can not be as effective as a vaccine to Covid but it could be a very good tool in tackling this pandemic. Hospitals have started to use Robots to cater Covid-19 patients during the treatment to reduce the human intervention and to also reduce the risk of further transmission of the virus. [16][17][18]

The possibility is endless in these machines, we can also include an infrared camera to detect the body temperature of people entering and if temperature is above recommended temperature a buzzer will sound and person can be stopped from entering and transmitting the virus (if he has further symptoms of Covid).

\section{REFERENCES}

[1] Easy Move INDIA "Corona Disinfection Tunnel" Retrieved June 16 2020 from "https://www.easymoveindia.in/corona-disinfection-tunnel.html"

[2] World Health Organization, "WHO Coronavirus Disease (COVID-19) Dashboard”, 2020. [Online]. Available: https://covid19.who.int/

[3] Physiopedia, "Corona virus Disease (COVID-19)", 2020. [Online]. Available: https://www.physio-pedia.com/Coronavirus_Disease_(COVID-19)

[4] Deepanshu T, et al, "A REVIEW ON IMPACT OF COVID-19 (SARSCoV-2) PANDEMIC ON ADDITIVE MANUFACTURING (3D

PRINTING)", IJSART Volume 6, Issue 6, June 2020, pp. 195-199, 2020.

[5] Money Control, "Unlock 1.0 Rules", Retrieved on June 16, 2020 from "https://bit.ly/3itU8MX"

[6] Ronald H Schmidt, "BASIC ELEMENTS OF EQUIPMENT CLEANING AND SANITIZING IN FOOD PROCESSING AND HANDLING

OPERATIONS", University of Florida, IFAS Extension, pp. 1-9, Publication July 1997, Revised March 2009.

[7] Levenson, Michael (19 March 2020). "Distilleries Race to Make Hand Sanitizer Amid Coronavirus Pandemic". The New York Times.

[8] Alcohol and Tobacco Tax and Trade Bureau. "Production of Hand Sanitizer by Distilled Spirits Permittees". The TTB Newsletter. US Department of the Treasury.
[9] "hand sanitizer - definition of hand sanitizer in English $\mid$ Oxford Dictionaries". Oxford Dictionaries $\mid$ English. Archived from the original on 18 June 2020.

[10] Aquatec, "RO Booster Pump",

"http://www.aquatec.com/pumps/pressureboosterpumps.html”, 2019.

[11] Spray Nozzle, (n.d.). In Wikipedia, Retrieved June 20, 2020 from https://en.m.wikipedia.org/wiki/Spray_nozzle

[12] Hand Sanitizer, (n.d.). In Wikipedia, Retrieved June 20, 2020 from https://en.wikipedia.org/wiki/Hand_sanitizer

[13] High-Density Polyethene, (n.d.). In Wikipedia, Retrieved June 20, 2020 from https://en.m.wikipedia.org/wiki/High-density_polyethylene

[14] PIR Sensor, "How PIRs Work", Retrieved from "https://learn.adafruit.com/pir-passive-infrared-proximity-motionsensor/how-pirs-work" on June 21,2020.

[15] StartUs Insights, "5 Top Robotic Disinfectant Solutions Impacting Public Safety During The Coronavirus Pandemic", Retrieved on June 20,2020 from "https://www.startus-insights.com/innovators-guide/5-toprobotic-disinfectant-solutions-impacting-public-safety-during-thecoronavirus-pandemic/"

[16] News Indian Express, "This robot uses UV rays to slay deadly coronaviruses" Published: 16th May 2020, retrieved on June 20, 2020 from https://bit.ly/3hNbXWX

[17] Times of India, "Central Railway engineer makes robot to help doctors fight Covid-19" by Vijay Pinjarkar on June 8, 2020. Retrieved on June 20, 2020 from https://bit.ly/2zQN4IR

[18] liveMint, "Adoption of robots in India hospitals to grow during and post Covid", by Abhijit Ahaskar on April 29,2020. Retrieved on June 21, 2020 from "https://bit.ly/2zOfPWq".

[19] PIR Sensor, (n.d.). In Wikipedia, Retrieved June 19, 2020 from https://en.wikipedia.org/wiki/Passive_infrared_sensor

[20] Guidelines, "Sanitizing public areas". Retrieved June 20, 2020 from https://www.mohfw.gov.in/

[21] Relays, (n.d.). In Wikipedia, Retrieved on June 19, 2020 from https://en.wikipedia.org/wiki/Relay

[22] Sprayer Supplies, "Sprayer Nozzle \& Tips". Retrieved on June 21, 2020 from https://www.sprayersupplies.com/

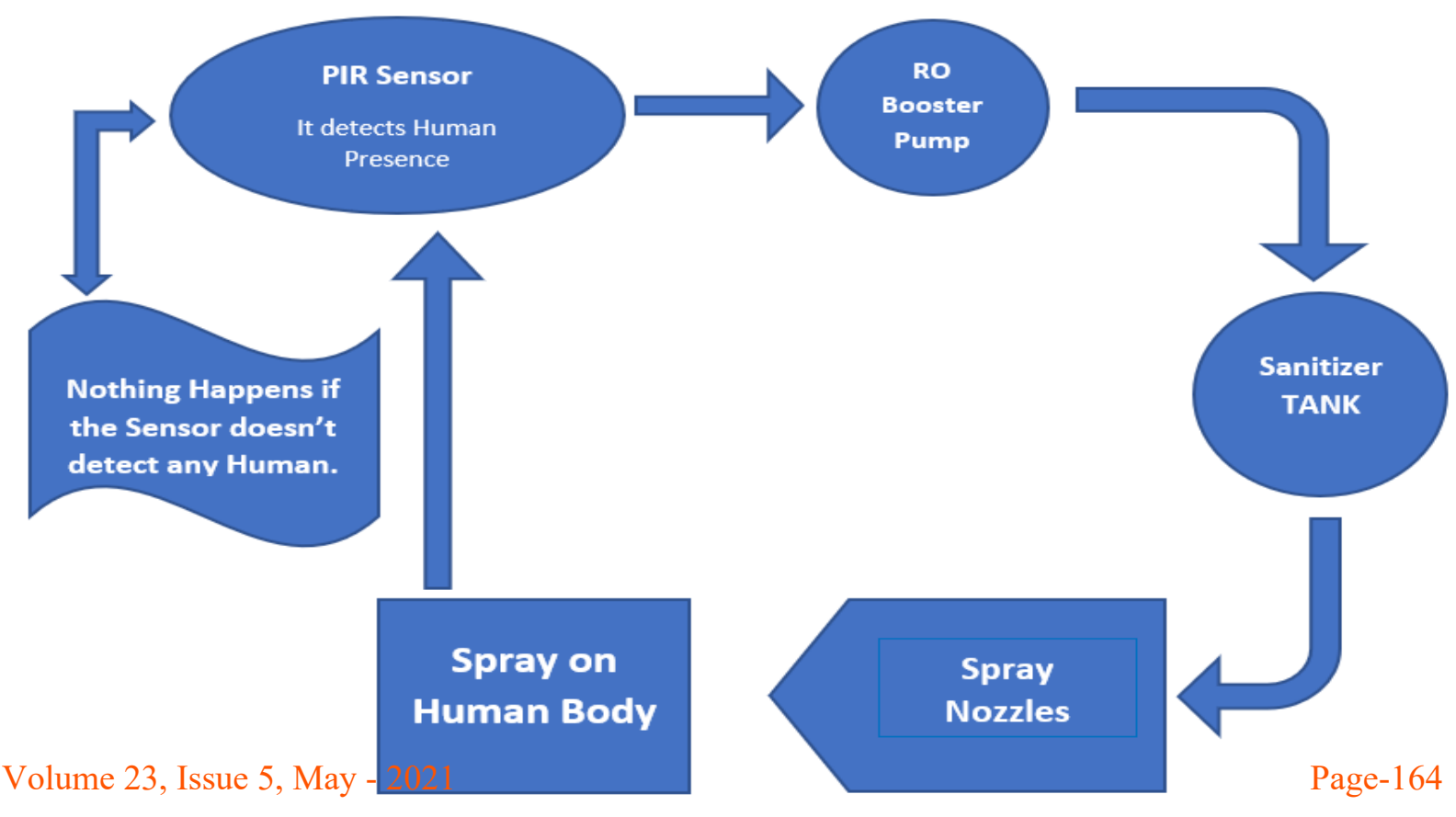

